Gut, 1973, 14, 125-132

\title{
Pain from distension of the pelvic colon by inflating a balloon in the irritable colon syndrome ${ }^{1}$
}

\author{
JAMES RITCHIE ${ }^{2}$ \\ From the Nuffield Department of Clinical Medicine, The Radcliffe Infirmary, Oxford, and the Nuffield \\ Institute for Medical Research, Oxford
}

SUMMARY The effects of inflating a balloon introduced through a sigmoidoscope to $35 \mathrm{~cm}$ in the pelvic colon have been observed and compared in 67 patients with the irritable colon syndrome and in 16 normal and constipated subjects acting as controls.

Inflation to $60 \mathrm{ml}$ caused pain in $6 \%$ of the controls at a mean diameter of $3.8 \mathrm{~cm}$ and in $55 \%$ of patients with the irritable colon syndrome (diameter $3.4 \mathrm{~cm}$ ). An estimate of gut wall tension at this volume of inflation showed it to be normal in patients with the irritable colon syndrome; the incidence of pain in relation to wall tension was increased nearly tenfold in the irritable colon group.

Inflation of the balloon to different volumes was normally painless to a maximum acceptable diameter which remained constant for each study under constant conditions; continued inflation eventually gave rise to pain without increasing the diameter. The pain was felt in the hypogastrium in $40 \%$, in one or both iliac fossae in $31 \%$, and in the rectum in $21 \%$; the other $8 \%$ felt pain in the back or elsewhere and there were no significant differences between clinical groups. Exceptionally, in $6 \%$ of the controls, and in $52 \%$ of patients with the irritable colon syndrome, pain occurred at balloon diameters that could still be increased by $10 \%$ or more with further inflation. This was probably the outcome of a low threshold for visceral pain in the section of bowel in contact with the balloon. Colonic hyperalgesia of this kind, possibly a random occurrence, may be an important contributory factor in the aetiology of the irritable colon syndrome.

Stretching of the colon by inflating a balloon in its lumen has long been known to cause pain (Bloomfield and Polland, 1931). This is probably caused partly by direct action on nerve endings in the wall of the viscus (Hertz, 1911; Payne and Poulton, 1927) and partly by increasing tension in its mesentery (Lennander, 1902; Meyer, 1919; Lewis, 1942). Little is known of any other effects.

This study was undertaken to examine different aspects of the sensory response of the colon to distension and its relationship to clinical dysfunction, especially in patients with the irritable colon syndrome.

${ }^{1}$ Presented in part at the British Society of Gastroenterology meeting at Aviemore, 29 September 1972.

Address for communications: The Nuffield Department of Clinical Medicine, The Radcliffe Infirmary, Oxford.

Received for publication 11 December 1972.

\section{Material and Methods}

A total of 167 patients from the wards and outpatients department of the Radcliffe Infirmary, Oxford, were studied by means of time-lapse cinefluorography with synchronized intraluminal pressure recording, as previously described (Ritchie, 1968a, 1972). They suffered from a number of clinical conditions, in particular the irritable colon syndrome, and included a number of normal and constipated subjects for comparison. Each subject had swallowed $100 \mathrm{ml}$ of Micropaque barium sulphate suspension about 13 hours before observations began, and all of them had a $15-\mathrm{ml}$ balloon included among the pressure-recording tube tips in the distal bowel, located at $35 \mathrm{~cm}$ from a marker defining the anal margin. In some instances the introduction of the tubes, which was done through a sigmoidoscope, was incomplete or unsatisfactory and the balloon was found to have been sited farther 
down the colon. These subjects have been excluded from the present study.

In the course of each set of observations the balloon was inflated to a volume of $60 \mathrm{ml}$, and to at least one other volume either greater or smaller. The onset of colonic pain was marked on the pressure tracing either by the observer or, latterly, by the subject himself. In assessing the response of the gut to distension, a pair of dividers was used on the magnified cinefluorogram of the inflated balloon, where this could be clearly seen, to determine the length of its smallest dimension at each volume tested. This measurement, corrected for the approximate depth of the balloon within the abdomen, was taken to represent the internal diameter of the gut at that point. Those in whom barium obscured the balloon have also been excluded from the study.

The first 100 patients with the irritable colon syndrome included 67 in whom the balloon was satisfactorily located at $35 \mathrm{~cm}$ from the anus and was sufficiently free of superimposed barium shadows to make accurate measurement possible. As Table I shows, their average age was 43 years and the clinical basis of the abdominal pain and bowel dysfunction had been established by rigorous exclusion of other recognized forms of organic disease. The control group consisted of 16 normal and constipated subjects of average age 50 . The criteria of normality in this context were an average frequency of bowel function less than twice a day with no known gastrointestinal disease in persons who had not previously complained of gastrointestinal symptoms. A more rigid distinction appears to be unattainable.

\begin{tabular}{lll}
\hline Clinical Group & No. in Group & Mean Age \\
\hline Normal and constipated subjects & 16 & 50 \\
Irritable colon syndrome & 67 & 43 \\
\hline
\end{tabular}

Table I Clinical material

\section{Results}

\section{BALLOON DIAMETER}

Inflating a balloon in the pelvic colon at a fixed distance of $35 \mathrm{~cm}$ from the anal margin with a standard 60-ml volume of air distended the gut wall to a variable degree in different subjects. In the group of 16 normal and constipated subjects, balloon diameters ranged from 3.1 to $4.5 \mathrm{~cm}$ with a mean value of $3.83 \pm 0.4 \mathrm{~cm}$ (Fig. 1).

Among 67 patients with the irritable colon syndrome, the range was even greater, from $2 \cdot 4$ to

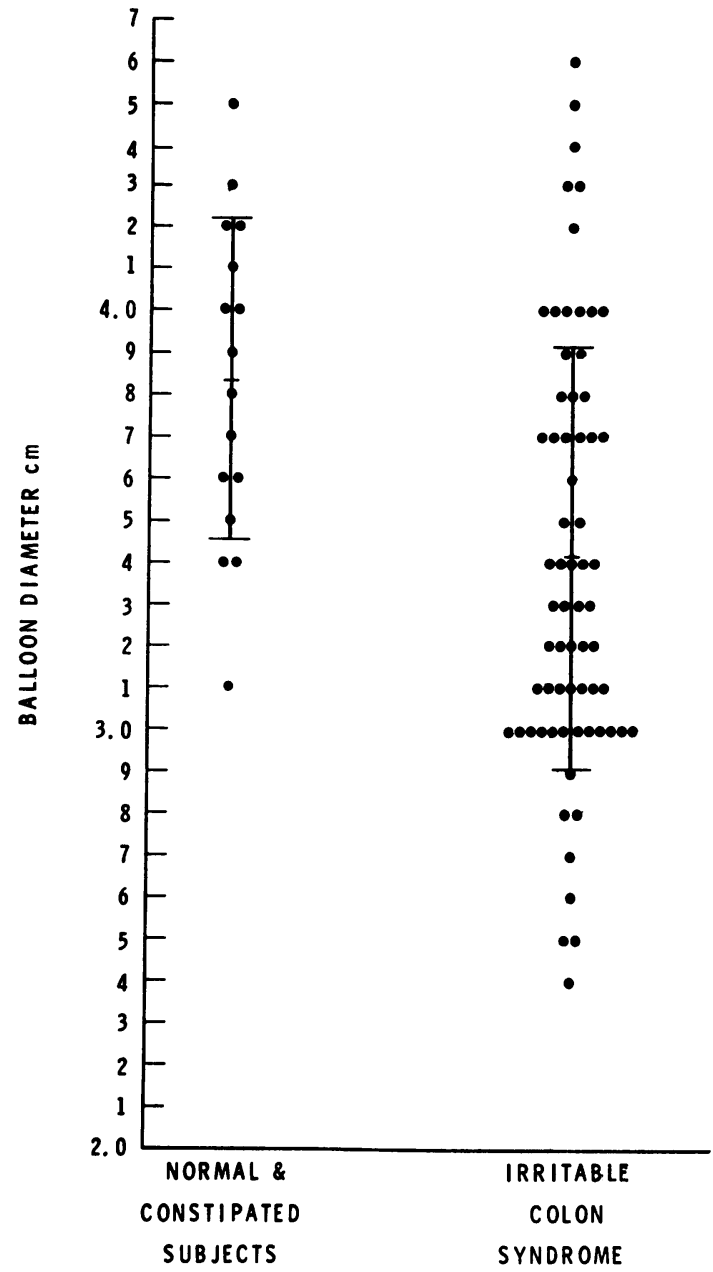

Fig. 1 Balloon diameters at $60 \mathrm{ml}$ inflation in the pelvic colon.

$4.6 \mathrm{~cm}$ with a mean of $3.41 \pm 0.5 \mathrm{~cm}$. This group does not appear to represent a homogeneous population with a normal distribution of balloon diameters; Fig. 1 suggests that it is made up of at least two distinct but overlapping components. Under these conditions the $t$ test cannot be used to assess the significance of the small increase in resistance to distension.

BALlOON VOLUME AND THE ONSET OF PAIN Among the 16 normal and constipated subjects pain associated with balloon inflation was only once observed at a volume of $60 \mathrm{ml}$; this represents a proportion of $6 \%$ (Fig. 2). Nine (56\%) complained of pain when the balloon contained about 100-150 $\mathrm{ml}$ of air. Among the 67 patients with the irritable 


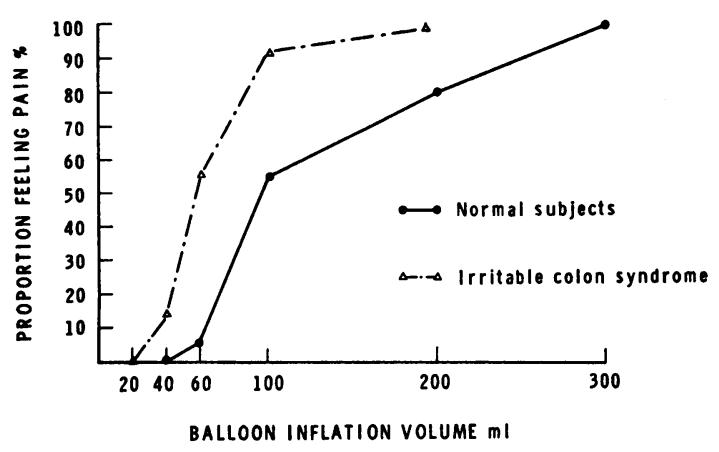

Fig. 2 Onset of pain at different volumes of balloon inflation.

colon syndrome $37(55 \%)$ felt pain with balloon inflation to $60 \mathrm{ml}$ or less. This represents a significantly higher proportion than occurred at that volume in the control group $\left(\chi^{2}=10 \cdot 6, \mathrm{n}=1\right.$, $P<0.001)$.

BALLOON PRESSURE AND GUT WALL TENSION It is not practicable under the conditions of this sort of study to measure tension in the bowel wall, but it is possible to estimate a 'tension multiple' to simplify comparisons between different clinical groups. This is done by measuring balloon diameter and pressure within the bowel at a standard interval after the standard $60-\mathrm{ml}$ inflation. The figure for intraluminal balloon pressure may then be compared with that obtained by inflating the same balloon with the same volume of air to the same diameter in an artificial gut consisting of a rigid lubricated tube. This second pressure reading represents the contribution made by tension in the balloon rubber. Figure 3 shows the balloon pressures recorded in different diameters of artificial gut at the standard inflationary volume of $60 \mathrm{ml}$. The product of balloon diameter multiplied by the difference between the balloon pressures obtained from inside and outside the gut is a multiple of the contractile tension in the bowel wall surrounding the balloon at the time of the cinefluorogram.

The mean diameter of the balloon inflated to $60 \mathrm{ml}$ in normal and constipated subjects was $3.8 \mathrm{~cm}$, and internal pressure in the balloon averaged $99 \mathrm{~mm} \mathrm{Hg}$

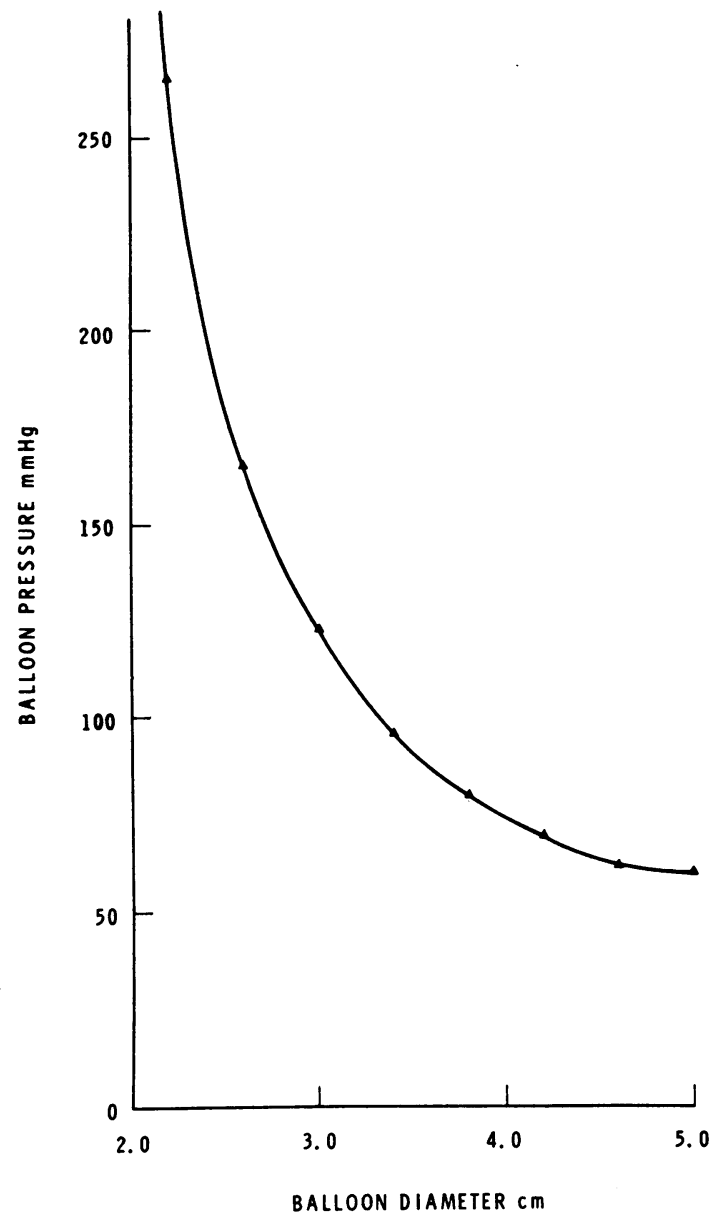

Fig. 3 Relating balloon pressures to diameter in a rigid tube.

12-15 seconds after the start of inflation. The mean pressure attributable to tension in the rubber wall of the balloon at a diameter of $3.8 \mathrm{~cm}$ was about $80 \mathrm{~mm}$ $\mathrm{Hg}$, so the difference between the two figures was $19 \mathrm{~mm} \mathrm{Hg}$. The mean tension multiple for the control group, therefore, which was proportional to the mean contractile tension in the distended bowel wall, was $3.8 \times 19=72$ units (Table II). The one normal

\begin{tabular}{|c|c|c|c|c|c|}
\hline Clinical Group & $\begin{array}{l}\text { Proportion with } \\
\text { Pain }(\%)\end{array}$ & $\begin{array}{l}\text { D Mean Diameter of } \\
\text { Balloon }(\mathrm{cm})\end{array}$ & $\begin{array}{l}P_{1} \text { Mean Pressure in } \\
\text { Gut }\end{array}$ & $\begin{array}{l}P_{2} \text { Mean Pressure in } \\
\text { Tube }\end{array}$ & $\begin{array}{l}\text { Tension Multiple } \\
=D\left(P_{1}-P_{2}\right)\end{array}$ \\
\hline $\begin{array}{l}\text { Normal controls } \\
\text { Irritable colon syndrome } \\
\text { Controls at } 120 \mathrm{ml}\end{array}$ & $\begin{array}{r}6 \\
56 \\
56\end{array}$ & $\begin{array}{l}3 \cdot 8 \\
3 \cdot 4 \\
4 \cdot 7\end{array}$ & $\begin{array}{r}99 \\
114 \\
124\end{array}$ & $\begin{array}{l}80 \\
95 \\
88\end{array}$ & $\begin{array}{r}72 \\
65 \\
169\end{array}$ \\
\hline
\end{tabular}

Table II Relative gut wall tension during standard $(60-\mathrm{ml})$ balloon inflation 
subject who felt pain at $60 \mathrm{ml}$ inflation, a somewhat tense and apprehensive young man, had a balloon diameter of $3.7 \mathrm{~cm}$ with internal pressure of 100 $\mathrm{mm} \mathrm{Hg} 15$ seconds after starting inflation. That represents a gut wall tension multiple of $3.7 \times 18=67$ units.

The mean diameter of the balloon at $60 \mathrm{ml}$ in 67 patients with the irritable colon syndrome was 3.4 $\mathrm{cm}$ and the average internal pressure after 12 to 15 seconds was $114 \mathrm{~mm} \mathrm{Hg}$. A comparable figure for the balloon alone at $3.4 \mathrm{~cm}$ diameter would be about $95 \mathrm{~mm} \mathrm{Hg}$, making the mean tension multiple associated with balloon inflation in this group $3.4 \times 19=65$ units.

A separate tension multiple was calculated for the control group at $120 \mathrm{ml}$ inflation, which was the average balloon volume at which $56 \%$ of these subjects first complained of pain. The mean balloon diameter under those conditions was $4.7 \mathrm{~cm}$ and the average difference between the two pressure readings was $36 \mathrm{~mm} \mathrm{Hg}$. This gave a figure for the tension multiple of 169 units.

\section{SITES OF PAIN SENSATION}

The region to which pain due to balloon inflation in the pelvic colon might be referred was unpredictable on any anatomical basis, and in four patients with the irritable colon syndrome pains occurred at two sites simultaneously. Pain was felt in the hypogastrium, more or less over the site of the balloon, on $35(40 \%)$ of the 87 occasions on which it was located (Table III). In $27(31 \%)$ of the subjects it was felt in one or both of the iliac fossae or lumbar regions and in about $21 \%$ it was felt in the ano-rectal region. A small proportion of subjects felt pain in the back or

\begin{tabular}{|c|c|c|}
\hline Site & $\begin{array}{l}\text { Number } \\
\text { Feeling Pain }\end{array}$ & Proportion (\%) \\
\hline$\underset{\text { Hypogastrium }}{\text { Rt }}$ & $\begin{array}{l}35 \\
11 ?\end{array}$ & 41 \\
\hline $\begin{array}{l}\text { Iliac fossae } \mathrm{Lt} \\
\text { Both }\end{array}$ & $\left.\begin{array}{r}14 \\
2\end{array}\right\}$ & 31 \\
\hline $\begin{array}{l}\text { Ano-rectal } \\
\text { Back } \\
\text { General or variable }\end{array}$ & $\begin{array}{r}18 \\
3 \\
4\end{array}$ & $\begin{array}{r}21 \\
3 \\
4\end{array}$ \\
\hline Total & 87 & 100 \\
\hline
\end{tabular}

Table III Distribution of pains from balloon inflation

more generally in the abdomen, and in one or two instances the site of pain reference changed with different degrees of balloon distension, or even with repeated inflations to the same volume. In general, patients who complained of pain somewhere in the lower abdomen as a clinical symptom tended to feel the pain of balloon inflation at the same site. There were no significant differences in the location of distension pains between one clinical group and another.

\section{BALLOON DIAMETERS AND PAIN}

Intraluminal balloon inflation to different volumes showed that the bowel could usually be distended to a maximum acceptable diameter (M A D) at which it gave no pain. Further inflation beyond that point only lengthened the balloon without measurable increase in its girth and sooner or later it became painful (Fig. 4). In this example, taken from an elderly woman with functional diarrhoea, balloon diameter remained the same, about $2.9 \mathrm{~cm}$, with inflation to $50 \mathrm{ml}$ (frame 2) and also to $100 \mathrm{ml}$ (frame

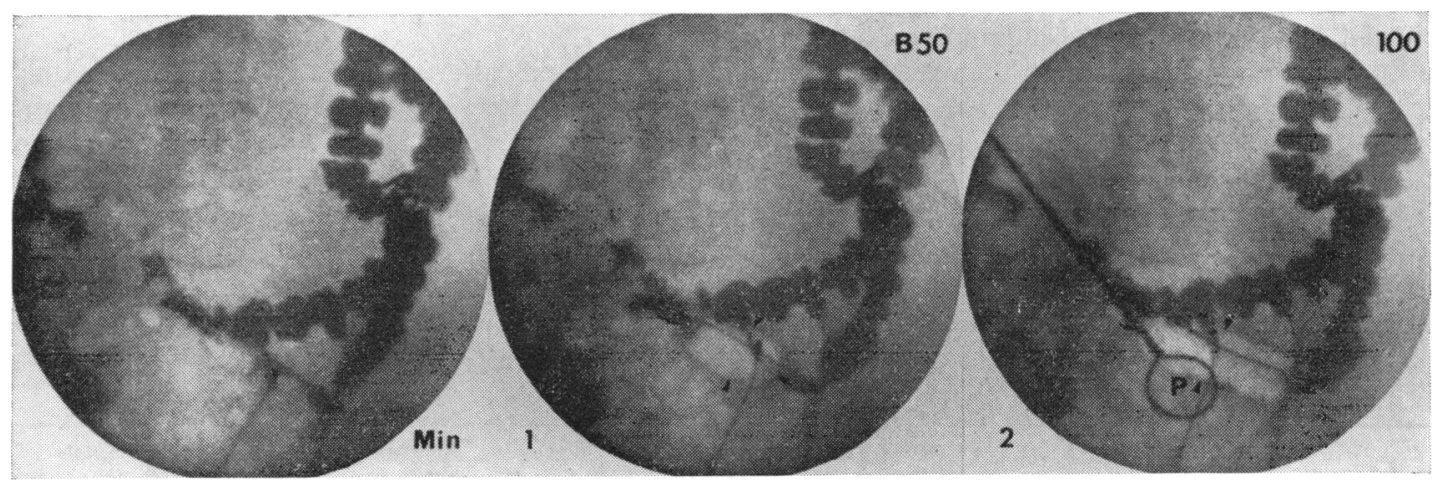

Fig. 4 Cinefluorograms taken at one-minute intervals show opacified contents in the colon down to the pelvic brim, where the 38-cm tube-tip is visible. The patient was an elderly woman with functional diarrhoea. In the second frame the balloon, located at about $33 \mathrm{~cm}$ from the anal margin, is inflated to $50 \mathrm{ml}$. Its diameter, as indicated by the arrows, was $2.9 \mathrm{~cm}$ and this caused no pain. A minute later a second inflation to $100 \mathrm{ml}$ greatly elongated the balloon but its diameter remained unchanged at $2.9 \mathrm{~cm}$. Pain was felt at this volume at the point marked by the ring. 
3) in successive minutes. The first inflation was painless, but the second was accompanied by hypogastric pain.

Balloon diameters representing the different volumes of inflation were not dependent on the time intervals from previous inflations nor on the order in which the different distending volumes were introduced. In Fig. 5, taken from film of a woman, of 38 with a four-year history of diarrhoea and pain in the left iliac fossa, currently in remission, pain was felt when balloon inflation reached $120 \mathrm{ml}$ (frame 5). In this instance the maximum acceptable diameter of $4.0 \mathrm{~cm}$ was reached at $20 \mathrm{ml}$ and the distension pain was felt at the site marked.

Continuing intraluminal balloon inflation beyond the volume at which pain was first felt did not usually increase its diameter (Fig. 6, frame 2); nor did the diameter alter appreciably when distension was maintained for several minutes (frame 4) though resistance to distension might vary in different circumstances. This subject was suffering from spastic constipation and her maximum acceptable diameter of $3.6 \mathrm{~cm}$ was probably reached at a volume of about $50 \mathrm{ml}$; inflation to 30 and $40 \mathrm{ml}$ (frames 5 and 6) gave rise to slightly smaller balloon diameters of 3.3 and $3.5 \mathrm{~cm}$ respectively and caused no pain, while a volume of $60 \mathrm{ml}$ (frame 1) was already painful. After eating lunch, gastrocolic responses enhanced resistance to circumferential stretching, and inflation volumes of 30 and $40 \mathrm{ml}$ only distended the gut to a diameter of $3 \cdot 1 \mathrm{~cm}$ (frames 7 and 8).

\section{PAIN AT SUBMAXIMAL BALLOON DIAMETERS}

Although most of the 16 control subjects did not experience pain until the bowel had been distended to a more or less constant maximum acceptable diameter (mean $=4.8 \mathrm{~cm}$ ), this was not always found to be so. In one member of the group $(6 \%)$, balloon inflation to $60 \mathrm{ml}$ gave rise to pain at a diameter of $3.7 \mathrm{~cm}$, and this diameter could subsequently be increased with further inflation to $4 \cdot 1$ $\mathrm{cm}$. If an arbitrary minimum increment of $10 \%$ over

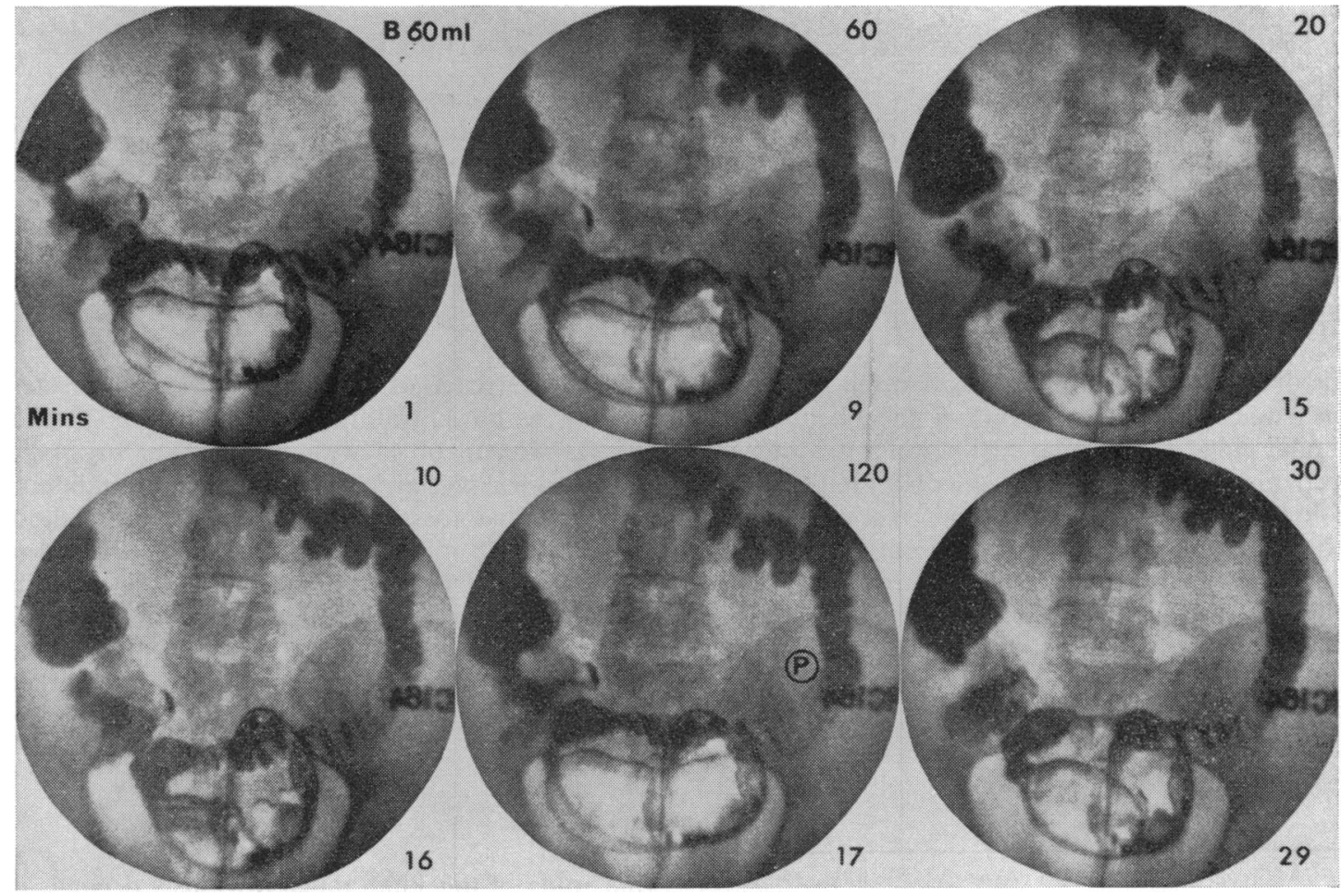

Fig. 5 Cinefluorograms were taken at intervals over half an hour in a woman of 38 with a four-year history of diarrhoea and pain in the left iliac fossa, currently in remission following treatment. They show successive inflations of the balloon to $60,60,20,10,120$, and $30 \mathrm{ml}$. The balloon reaches its maximum acceptable diameter $(M A D)$ of $4.0 \mathrm{~cm}$ at a volume of $20 \mathrm{ml}$ and merely elongates with further inflation. Pain was felt at the site marked only when the volume reached $120 \mathrm{ml}$, the diameter still being $4.0 \mathrm{~cm}$. 


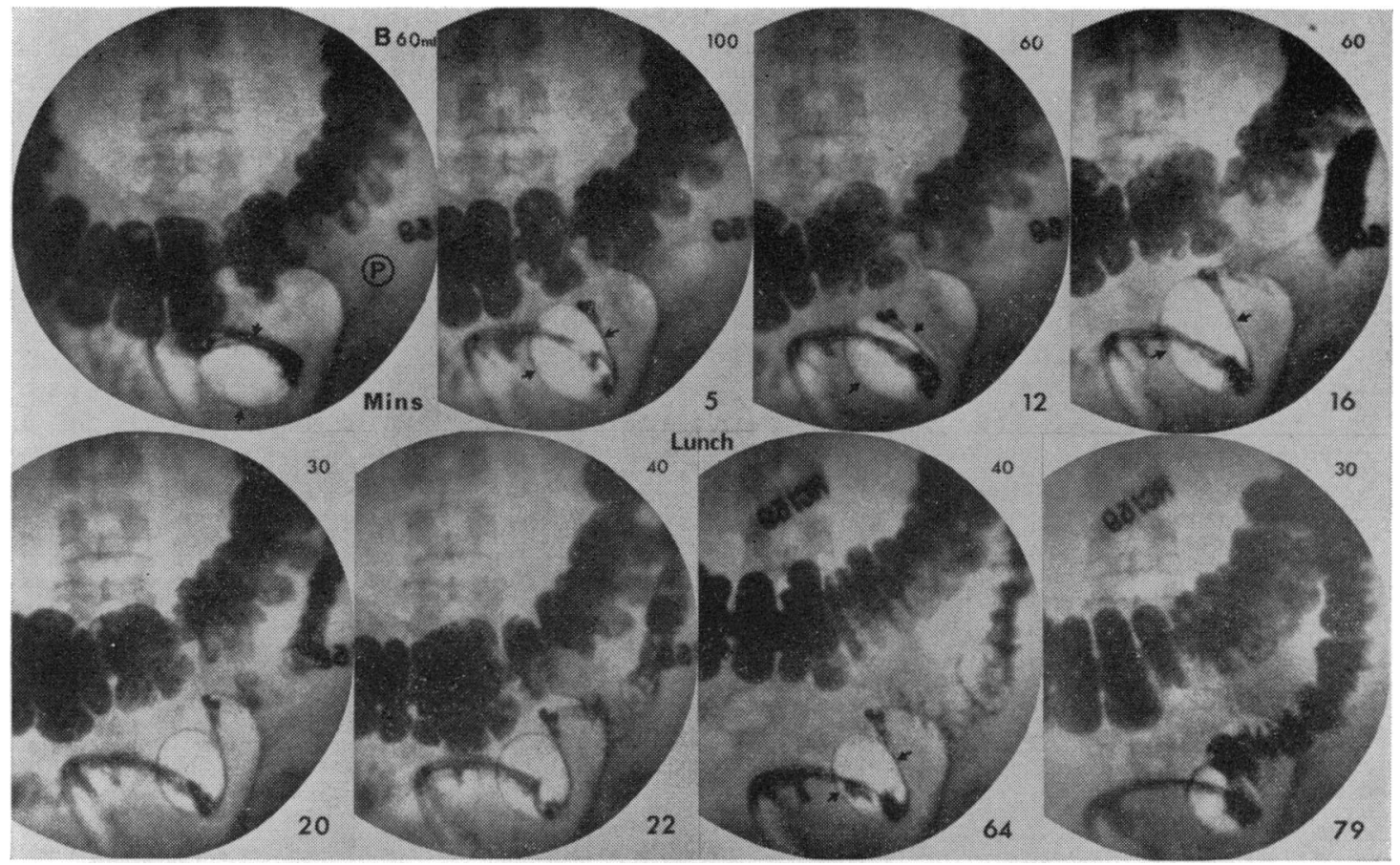

Fig. 6 Cinefluorograms show balloon inflation in the pelvic colon of a patient with spastic constipation. The first frame was taken only two seconds after inflation to $60 \mathrm{ml}$, when the diameter was $3.6 \mathrm{~cm}$ and pain was already present in the left iliac fossa. The second inflation, to $100 \mathrm{ml}$, produced the same diameter and pain. The third, to $60 \mathrm{ml}$ again 12 seconds after inflation, and the fourth 180 seconds after inflation both show a diameter of $3.6 \mathrm{~cm}$ with the same pain. The fifth and sixth frames show inflations to 30 and $40 \mathrm{ml}$ respectively, which were painless and reached diameters of 3.3 and $3.5 \mathrm{~cm}$. When these two inflations were repeated after eating lunch the balloon diameter in both instances was only $3.1 \mathrm{~cm}$; the gastrocolic response had evidently enhanced the resistance of this patient's bowel wall to distension.

the diameter at which pain was first felt were set as the standard for demonstrating the phenomenon, similar pains with submaximal bowel distension were recognizable in 30 out of 58 patients with the irritable colon syndrome (Table IV). This represents a proportion of $52 \%$ which is significantly higher than that of the controls $\left(\chi^{2}=8 \cdot 6, \mathrm{n}=1, \mathrm{P}<0.005\right)$. Nine of the patients had to be excluded from this part of the study; this was either because the volumes of inflation that were tested were unsuitable for demonstrating the phenomenon, or because the balloon had moved down the gut, or its diameter had become obscured by barium.

\begin{tabular}{llll}
\hline Clinical Group & $\begin{array}{l}\text { Numbers } \\
\text { Included }\end{array}$ & $\begin{array}{l}\text { No. with } \\
\text { Pain }\end{array}$ & $\begin{array}{l}\text { Proportion } \\
(\%)\end{array}$ \\
\hline $\begin{array}{l}\text { Normal and constipated subjects } \\
\text { Irritable colon syndrome }\end{array}$ & 16 & 1 & 6 \\
\hline
\end{tabular}

Table IV Prevalence of pain from submaximal balloon distension
The occurrence of pain with submaximal distension of the bowel.wall is illustrated in Fig. 7, taken from a woman of 44 with a three-year history of urgent morning diarrhoea and generalized abdominal, right iliac fossa, and ano-rectal pains. Balloon inflation to $40 \mathrm{ml}$ (frame 2, upper row) reached an average diameter of $2.4 \mathrm{~cm}$ and was accompanied by ano-rectal griping pain. Reinflation three minutes later to $60 \mathrm{ml}$ reproduced the pain, but the diameter of the balloon had increased by $16 \%$ to $2.8 \mathrm{~cm}$ (frame 2 , lower row).

\section{Discussion}

\section{METHOD}

In a study of this kind, much obviously depends on the accuracy of measurement of the balloon diameter. Fortunately, provided that the outline of the balloon is not obscured by barium, this presents no special problems. Whatever the balloon's length or its angle of presentation may be, the shortest 


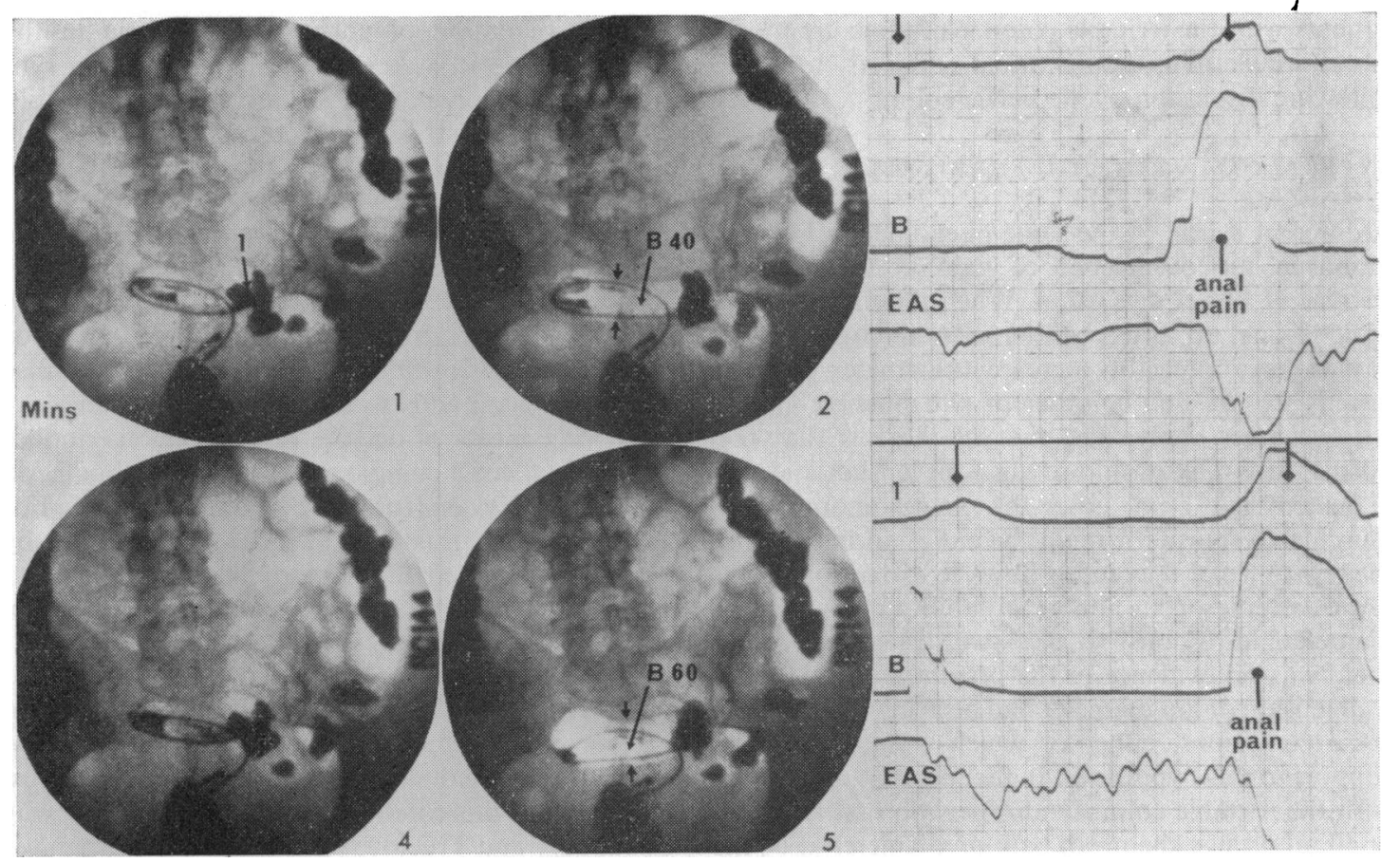

Fig. 7 Cinefluorograms with synchronized intraluminal pressure recordings were taken from a woman of 44 with a three-year history of urgent morning diarrhoea with frequent, severe, and widespread abdominal pains. The tracings record pressure from tip 1 at $38 \mathrm{~cm}$, from the balloon at $33 \mathrm{~cm}$, and from the anal sphincter at about $2 \mathrm{~cm} ; 5 \mathrm{~mm}$ deflection represents $10 \mathrm{~mm} \mathrm{Hg}$ pressure change in the open-ended tubes and $25 \mathrm{~mm} \mathrm{Hg}$ in the balloon. On the time scale a 5-mm square is traversed in four seconds. Balloon inflation to $40 \mathrm{ml}$ (frame 2 of the upper row) caused ano-rectal griping pain at an average diameter of $2.4 \mathrm{~cm}$. Three minutes later inflation was repeated and extended to $60 \mathrm{ml}$, causing a similar but more severe pain and producing a balloon diameter of $2.8 \mathrm{~cm}$, an increase of $16 \%$.

distance across the magnified oval gas shadow must represent its diameter. The correction of this figure to allow for the distance of the balloon from the phosphor of the image intensifier can only be approximate; it is based on an estimate of the depth in each subject's abdomen, and this may give rise to arror, possibly up to $10 \%$ in either direction, in the calculation of diameter between one subject and another. However, the correction factor must be the same for all measurements made in the course of a single study, unless the balloon has moved; if this does happen between one observation and another, the bowel wall in contact with the balloon must also have changed its characteristics and the figures for that study have to be discarded. Error between individual subjects will tend to be balanced within each clinical group.

\section{DISTRIBUTION OF PAINS}

Bloomfield and Bolland (1931) succeeded in inflating balloons in the descending and pelvic colon in nine intact subjects. Six felt pain centrally in the lower abdomen, one in the right iliac fossa, and two in the left. None mentioned ano-rectal discomfort. Their findings also emphasize the wide range of balloon volumes over which pain may first be felt: one of the subjects $(11 \%)$ needed only $20 \mathrm{ml}$ inflation and one needed $500 \mathrm{ml}$. The remainder felt pain at from 100 to $150 \mathrm{ml}$.

\section{THRESHOLDS FOR DISTENSION PAIN}

The present study has shown that balloon inflation to $60 \mathrm{ml}$ gave rise to a mean gut wall tension multiple after 12 to 15 seconds of 72 units among the control subjects, and that in one of them this was enough to cause pain. Among patients with the irritable colon syndrome the same degree of inflation provoked a slightly lower level of tension in the gut wall and nearly ten times the normal proportion complained of pain. A pain incidence as high as this $(56 \%)$ was only recorded in the control group when the volume of the balloon inflation had been doubled to $120 \mathrm{ml}$, and contractile tension in the bowel wall had increased by an even wider margin. It is clear that 
patients with the irritable colon syndrome are much more susceptible than normal subjects to pain following distension of the pelvic colon.

HYPERALGESIA IN THE IRRITABLE COLON SYNDROME

A different aspect of the same phenomenon is to be found in the occurrence of pain at submaximal degrees of bowel distension. When the introduction of additional air into a balloon after the initial onset of pain can appreciably increase its diameter, and not just its length, one or other of two possible explanations must apply. The first of these is that the normal interrelationship of gut wall tension and gut diameter has been upset by some anomaly of muscular response; it might be either an increase in the resistance of the muscle fibres to distension at the lower volume or an abnormal lability of maximum diameters in response to excessive stretch. However, there was no evidence in the present study that gut wall tension or gut diameter had been increased under these conditions, either of which would have lent support to this hypothesis. In fact, among 10 patients with the irritable colon syndrome who first felt pain at $40 \mathrm{ml}$ or less, the mean balloon diameter at $60 \mathrm{ml}$ was still only $3 \cdot 1 \mathrm{~cm}$, less than the average for the group as as whole. In the same way, among nine patients in whom the pain with submaximal distension first occurred as the balloon was inflated to the standard 60-ml volume, its mean diameter was $3.3 \mathrm{~cm}$ and the pressure attributable to the gut wall averaged $12 \mathrm{~mm} \mathrm{Hg}$. This represents a mean tension multiple of less than 40 units, only one-quarter of that at which a majority of the control subjects started to feel pain. These figures rather support the alternative explanation that the occurrence of pain at submaximal degrees of distension shows that the visceral pain threshold is low.

Hyperalgesia of this sort appears to be different from that which develops in relation to other forms of painful stimulation like heat applied to the skin. Hyperalgesia in the context of heat pain only occurs when noxious stimuli like sunburn (Lewis, 1942) release bradykinin and other pain substances in the damaged tissue to sensitize its nerve endings. Sensitization hyperalgesia may occur in the stomach, where the mucosal pain threshold is normally very high but is greatly reduced by inflammation (Wolff and Wolf, 1958); however, by definition, there is no inflammatory activity in the bowel wall in the irritable colon syndrome.
The explanation of colonic hyperalgesia in the form in which it is seen in the irritable colon syndrome may simply be that variations in the threshold of gut pain are distributed at random over the whole population about a theoretical median norm. Those in whom the pain threshold is low at some point in the bowel are more likely than others to experience pain when that section is distended in the course of propulsion or contracts after a meal (Ritchie, 1968b). Any abnormality, structural or functional, that tends to increase their intraluminal pressures and so raise gut wall tension adds to the likelihood of pain.

Such a concept of degrees of hyperalgesia implies in each instance a comparable degree of hypoalgesia at the opposite end of the distribution curve. For obvious reasons it is difficult to demonstrate this by means of a simple balloon study, but Lim and Guzman (1968) found that even intraperitoneal kinin injections were painless in $7 \%$ of their volunteers.

When hyperalgesia is superimposed on a motor dysfunction in patients with the irritable colon syndrome, they are less likely to be directly relieved by sedation and anticholinergics, the standard treatment for this condition. That would explain why Chaudhary and Truelove (1962) found the prognosis to be worse in cases where pain was a prominent feature. It might be worthwhile to look for more direct means of raising the visceral pain threshold as part of the treatment of the irritable colon syndrome.

\section{References}

Bloomfield, A. L., and Polland, W. S. (1931). Experimental referred pain from the gastrointestinal tract. Part II. Stomach, duodenum, and colon. J. clin. Invest., 10, 453-473.

Chaudhary, N. A., and Truelove, S. C. (1962). The irritable colon syndrome. Quart. J. Med., 31, 307-322.

Hertz [Hurst], A. F. (1911). The Sensibility of the Alimentary Canal (Goulstonian Lectures). H. Frowde and Hodder and Stoughton, London.

Lennander, K. G. (1902). Beobachtungen über die Sensibilität in der Bauchhöhle. Mitt. Grenzgeb. Med. Chir., 10, Heft 1/2.

Lewis, T. (1942). Pain. Macmillan, New York.

Lim, R. K. S., and Guzman, F. (1968). Manifestations of pain in analgesic evaluation in animals and man. In Pain, edited by A. Soulairac, J. Cahn, and J. Charpentier, pp. 119-152. Academic Press, London and New York.

Meyer, A. W. (1919). Experimentelle Untersuchungen über die Sensibilităt von Magen und Darm. Dtsch.Z. Chir., 151, 153-163.

Payne, W. W., and Poulton, E. P. (1927). Experiments on visceral sensation: relation of pain to activity in human oesophagus. J. Physiol. (Lond.), 63, 217-241.

Ritchie, J. A. (1968a). Colonic motor activity and bowel function Part I. Normal movement of contents. Gut, 9, 442-456.

Ritchie, J. A. (1968b). The gastrocolic response to food. Digestion, 1, 15-21.

Ritchie, J. A. (1972). Mass peristalsis in the human colon after contact with oxyphenization. Gut, 13, 211-219.

Wolff, H. G., and Wolf, S. (1958). Pain, 2nd ed. Thomas, Springfield, Illinois, and Blackwell, Oxford. 